Document downloaded from:

http://hdl.handle.net/10251/64186

This paper must be cited as:

López Nieto, JM.; Solsona Espriu, BE.; Grasselli, RK.; Concepción Heydorn, P. (2014). Promoted $\mathrm{NiO}$ catalysts for the oxidative dehydrogenation of ethane. Topics in Catalysis. 57(14-16):1248-1255. doi:10.1007/s11244-014-0288-2.

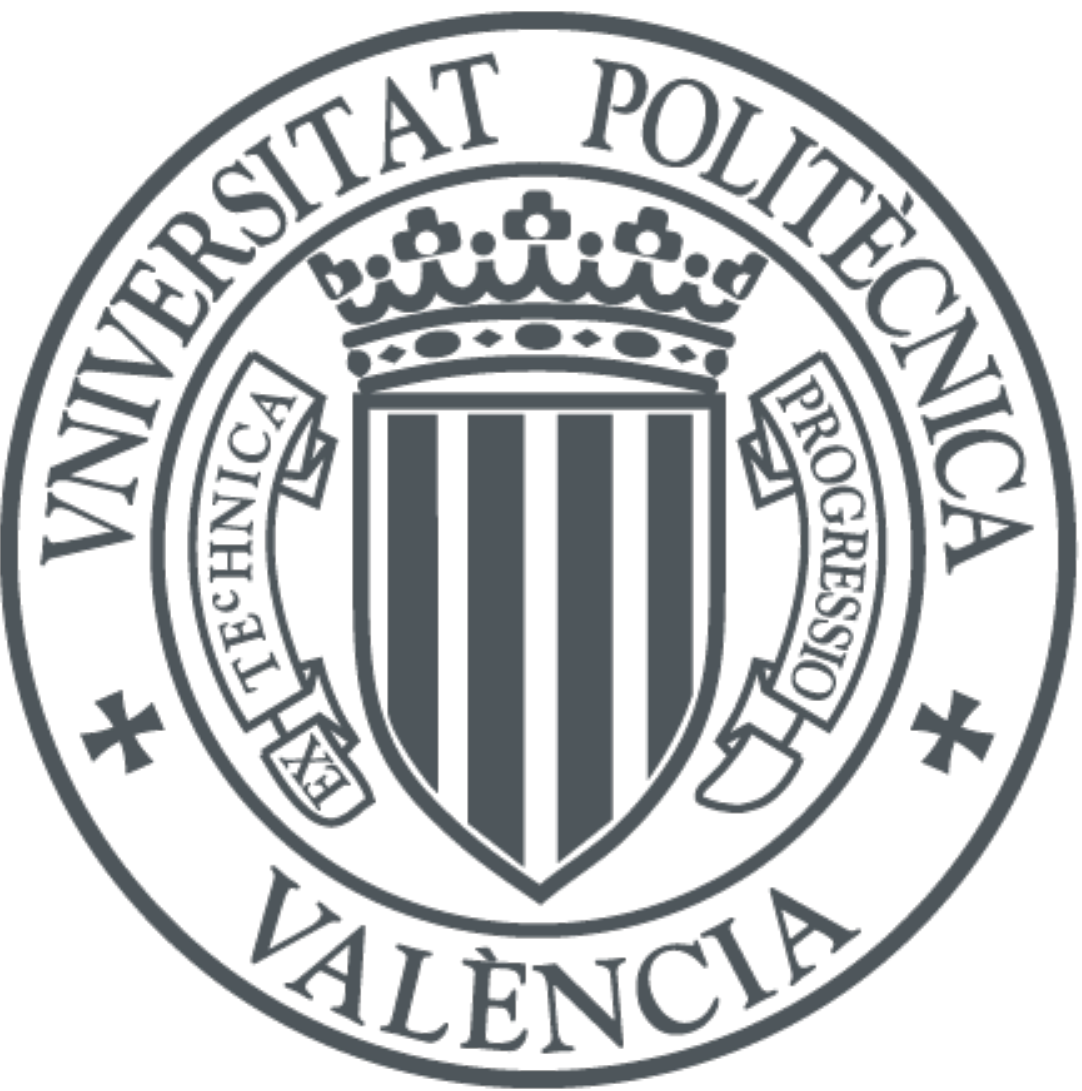

The final publication is available at

http://dx.doi.org/10.1007/s11244-014-0288-2

Copyright Springer Verlag (Germany)

Additional Information 


\section{Promoted NiO catalysts for the oxidative dehydrogenation of ethane}

José M. López Nieto ${ }^{a *}$, Benjamín Solsona ${ }^{\text {b* }}$, Robert K. Grasselli ${ }^{\text {c,d }}$, Patricia Concepción ${ }^{\text {a }}$

${ }^{a}$ Instituto de Tecnología Química, UPV-CSIC, Campus de la Universidad Politécnica de Valencia, Av. Naranjos s/n, 46022 Valencia, Spain.

b Departamento de Ingeniería Química, Universitat de Valencia, c/ Dr. Moliner 50, 46100, Burjassot, Spain.

${ }^{\mathrm{c}}$ Center for Catalytic Science and Technology, University of Delaware, Newark, DE, USA

d Department of Chemistry, Technische Universität München, München, Germany (rkgrasselli@yahoo.com)

* To whom correspondence should be addressed: FAX: +34963877809

Email address: jmlopez@itq.upv.es; benjamin.solsona@uv.es 


\begin{abstract}
Metal oxide promoted $\mathrm{NiO}$ catalysts with a $\mathrm{Ni} /(\mathrm{Me}+\mathrm{Ni})$ atomic ratio 0.92 have been investigated for the oxidative dehydrogenation of ethane. The catalysts were prepared through the evaporation of stirred ethanolic solution of metal salts and oxalic acid, and finally calcined in air at $500{ }^{\circ} \mathrm{C}$ for $2 \mathrm{~h}$. These materials have been characterized by several techniques ( $\mathrm{N}_{2}$-adsorption, X-ray diffraction, X-Ray Photoelectron Spectroscopy and Fourier Transformed Infrared Spectroscopy of adsorbed CO). The NiO crystal size and the nature of surface sites are strongly influenced by the acid/base character of the metal oxide promoters, which on the other hand have a great impact on the selectivity to ethylene. Indeed, a parallelism between the selectivity to ethylene and the number/strength of acid sites on the surface of the catalysts is observed, arguing about the importance of the presence of acid sites of optimum strength on the catalyst surface to attain the desired selectivity to ethylene.
\end{abstract}




\section{INTRODUCTION}

Ethylene is considered as the most important building block in petrochemistry. In spite of the current economical crisis the demand for ethylene has continuously increased until 2012, although since then a slight decrease in the ethylene production has been observed [1,2].

Currently, ethylene is mainly produced by "steam cracking” of hydrocarbons which is the most energy-consuming process in the chemical industry [3]. A possible industrial alternative is the oxidative dehydrogenation of ethane to ethylene (ODHE), an exothermic process which can operate at only $300-400^{\circ} \mathrm{C}$ in which the catalyst deactivation by coke can be minimized because of the presence of molecular oxygen as an oxidant in the reactor feed $[4,5]$.

For many years the typical catalysts for the ODHE reported in the literature consisted of vanadium oxide supported on different metal oxides [6,7] and recently unconventional materials such as nanocatalysts [8,9], catalysts derived from heteropolyacids [10] and carbon nanotubes [11] have demonstrated to be efficient in this reaction but their catalytic performance is still far from the best catalytic systems, which are NiO-based catalysts [12-22] and MoVNb-mixed metal oxide materials [23-26].

Pure nickel oxide is a low cost oxide that activates ethane (and other short chain alkanes) in the presence of molecular oxygen with high activity at relatively low reaction temperatures. However, most of the ethane is transformed into carbon dioxide [12]. As a catalyst for hydrocarbons combustion $\mathrm{NiO}$ is of rather limited interest as it exhibits lower reactivity than other metal oxides such as cobalt oxide and especially lower than catalysts based on noble metals such as platinum or palladium [27].

However, if nickel oxide is promoted with several elements [12-21] or supported on metal oxides [28] with appropriate characteristics the catalytic performance drastically 
changes as the formation of carbon dioxide decreases and the selective transformation to ethylene greatly increases. Therefore, ethylene can be efficiently obtained from ethane in the presence of oxygen using promoted nickel oxide catalysts. The most effective promoters of $\mathrm{NiO}$ reported in the literature are niobium [12, 14-17] and tin [18].

Lemonidou et al. [15] studied a series of Ni-based mixed oxides with doping metals varying from low $(+1)$ to high valence $(+5)$ elements and clearly demonstrated the different impact the nature of the dopants has on the catalytic performance in the ODHE. It was shown that the promotion with cations of lower or equal valence $\left(\mathrm{Li}^{+}, \mathrm{Mg}^{2+}\right)$ increases the non-stoichiometric oxygen in $\mathrm{NiO}\left(\mathrm{Ni}^{3+}\right.$ species). However, when the cation added has a higher valence $\left(\mathrm{Al}^{3+}, \mathrm{Ga}^{3+}, \mathrm{Ti}^{4+} \mathrm{Nb}^{5+}, \mathrm{Ta}^{5+}\right)$, the positive $\mathrm{p}^{+}$hole concentration decreases and a removal of unselective high oxidation state nickel oxide take place. Consequently, a correlation between the valence of the dopant cation and the selectivity to ethylene was established.

Recently, for Sn doped NiO it was observed a correlation between the selectivity to ethylene with and the Satellite1/Main-peak ratio determined by XPS was observed for Sn doped NiO [18], suggesting that non-stoichiometric Ni species seems to favor the ethane combustion, while stoichiometric $\mathrm{Ni}^{2+}$ are is involved in the selective ODH of ethane. On the other hand, by Additionally, ${ }^{16} \mathrm{O}_{2}{ }^{18} \mathrm{O}_{2}$ isotopic exchange experiments it has been have shown that the addition of dopants reduces the amount of electrophilic oxygen species which are generated on surface defects $[14,18]$. Thus a clear correlation between surface sites and the addition of several various promoters should be expected possible.

The purpose of the present work is: i) to show the influence on the selectivity to ethylene in the ODHE process of adding various promoters to $\mathrm{NiO}$ ( $\mathrm{Al}, \mathrm{Sn}, \mathrm{K}, \mathrm{Ce}, \mathrm{Zr}$, $\mathrm{Ce}+\mathrm{Zr}, \mathrm{La}, \mathrm{Nb}$ ) some of which have to the best of our knowledge not as yet been reported 
in the literature ( $\mathrm{La}$ and $\mathrm{Zr}$ ), and ii) to attempt to elucidate the influence that different cations promoters have on the nature of Ni surface sites, in order to explain the promoter effects of the dopands on the catalytic behaviour of the NiO catalysts. For that purpose surface sensitive spectroscopy (XPS and FTIR of probe molecule) has been used.

\section{EXPERIMENTAL}

\subsection{Catalysts preparation}

Promoted NiO mixed metal oxides catalysts were prepared through the evaporation at $60{ }^{\circ} \mathrm{C}$ of a stirred ethanolic solution of nickel nitrate, $\mathrm{Ni}\left(\mathrm{NO}_{3}\right)_{2} \cdot 6 \mathrm{H}_{2} \mathrm{O}$ (Sigma-Aldrich), and a salt of the promoter: $\mathrm{Al}\left(\mathrm{NO}_{3}\right)_{3} \cdot \mathrm{xH}_{2} \mathrm{O}$ for $\mathrm{Al}, \mathrm{SnC}_{2} \mathrm{O}_{4}$ for $\mathrm{Sn}$, ammonium niobate (V) oxalate for $\mathrm{Nb}$, Lanthanum (III) oxalate hydrate for La, $\mathrm{Ce}\left(\mathrm{NO}_{3}\right)_{3} .6 \mathrm{H}_{2} \mathrm{O}$ for $\mathrm{Ce}, \mathrm{Zr}\left(\mathrm{NO}_{3}\right)_{2} .5 \mathrm{H}_{2} \mathrm{O}$ for $\mathrm{Zr}$, and $\mathrm{KNO}_{3}$ for $\mathrm{K}$, all of them from SigmaAldrich. Oxalic acid was added to the solution with an oxalic acid/( $\mathrm{Ni}+$ metal promoter) molar ratio of 1 for consistency. The solids were dried overnight at $120{ }^{\circ} \mathrm{C}$ and finally calcined in static air for $2 \mathrm{~h}$ at $500{ }^{\circ} \mathrm{C}$.

The catalysts have been named as $\mathrm{NiX}$, where $\mathrm{X}$ is the corresponding promoter (Al, Sn, K, Ce, Zr, La, Nb). The amount of promoter has been fixed in $\mathrm{X} /(\mathrm{X}+\mathrm{Ni}$ ) at. ratio of 0.08 , which is close to the optimal for attaining the highest selectivity to ethylene for any of the promoters employed. Two more promoted nickel oxide catalysts were prepared using two promoters $\mathrm{Ce}$ and $\mathrm{Zr}$ and keeping in both cases the $(\mathrm{Ce}+\mathrm{Zr}) /(\mathrm{Ce}+\mathrm{Zr}+\mathrm{Ni})$ atomic ratio in 0.08 . These two catalysts have been named as NiCe-Zr and NiZr-Ce presenting a $\mathrm{Ce} /(\mathrm{Ce}+\mathrm{Zr})$ atomic ratio of 0.8 and 0.2 respectively.

\subsection{Characterization techniques}


Catalyst surface areas were determined by multi-point $\mathrm{N} 2$ adsorption at $77 \mathrm{~K}$, in a Micromeritics ASAP 2000 instrument. The data were treated in accordance with the BET method.

Average chemical composition of catalysts was determined by inductively couple plasma (ICP).

Powder X-ray diffraction (XRD) was used to identify the crystalline phases present in the catalysts. An Enraf Nonius FR590 sealed tube diffractometer, with a monochromatic CuKa1 source operated at $40 \mathrm{kV}$ and $30 \mathrm{~mA}$ was used. The particle sizes have estimated from XRD data using the Scherrer formula. This formula has been applied to peaks related to (101), (012), (113), and (024) crystal planes of NiO.

X-ray photoelectron spectra were collected using a SPECS spectrometer with a MCD-9 detector and using a non-monochromatic AlKa (1486.6 eV) X-ray source. Spectra were recorded using analyzer pass energy of $50 \mathrm{eV}$, an X-ray power of $200 \mathrm{~W}$, and under an operating pressure of 10-9 mbar. During data processing of the XPS spectra, binding energy (BE) values were referenced to C1s peak (284.5 eV). Spectra treatment has been performed using the CASA software.

IR spectra of adsorbed CO were recorded at low temperature $\left(-176^{\circ} \mathrm{C}\right)$ with a Nexus 8700 FTIR spectrometer using a DTGS detector and acquiring at $4 \mathrm{~cm}^{-1}$ resolution. An IR cell allowing in situ treatments in controlled atmospheres and temperatures from $176{ }^{\circ} \mathrm{C}$ to $500{ }^{\circ} \mathrm{C}$ has been connected to a vacuum system with gas dosing facility. For IR studies the samples were pressed into self-supported wafers and treated at $250{ }^{\circ} \mathrm{C}$ in Oxygen flow (20 ml min ${ }^{-1}$ ) for $1.5 \mathrm{~h}$ followed by evacuation at $300^{\circ} \mathrm{C}, 10^{-4} \mathrm{mbar}$ for $1 \mathrm{~h}$. After activation the samples were cooled down to $-176^{\circ} \mathrm{C}$ under dynamic vacuum conditions followed by CO dosing at increasing pressure (0.4-8.5 mbar). IR spectra were recorded after each dosage. 


\subsection{Catalytic tests}

The catalytic tests in ethane oxidation were carried out in a tubular isothermal flow reactor in the $300-450{ }^{\circ} \mathrm{C}$ temperature range. The feed corresponds to a mixture consisting of $\mathrm{C}_{2} / \mathrm{O}_{2} / \mathrm{He}$ with a molar ratio of $3 / 1 / 29$. Typical reaction conditions used were $0.5 \mathrm{~g}$ of catalyst and $25 \mathrm{ml} / \mathrm{min}$, although both the catalyst amounts loaded and the total flows used were largely varied to achieve different ethane conversions at a given reaction temperature. Samples were introduced in the reactor diluted with silicon carbide in order to keep a constant volume in the catalytic bed. Reactant and products were analyzed by gas chromatography using two packed columns: (i) molecular sieve $5 \AA$ (2.5 m); and (ii) Porapak Q (3 m). Ethylene and carbon dioxide were the main reaction products detected regardless of the catalysts tested. $\mathrm{CO}$ was also identified but in general with low selectivity. Blank runs showed no conversion in the range of reaction temperatures employed.

\section{RESULTS AND DISCUSSION}

The main C-containing reaction products observed in the oxidative dehydrogenation of ethane for pure and promoted $\mathrm{NiO}$ catalysts have been ethylene and $\mathrm{CO}_{2}$. $\mathrm{CO}$ has also been detected for some catalysts but in very low concentrations. Table 1 shows, comparatively the selectivity to ethylene of promoted catalysts achieved at a conversion of ethane of $10 \%$.

$\mathrm{Nb}$ - and Sn-promoted $\mathrm{NiO}$ exhibit the higher selectivity range to ethylene, whereas $\mathrm{NiO}$ and $\mathrm{K}$-promoted $\mathrm{NiO}$ catalysts lie in the lower selectivity range to ethylene.

Figure 1 shows the relationship between the selectivity to ethylene and different parameters such as the valence of the dopant (Fig. 1a) and the isoelectric point of the 
doping metal oxide added (Fig. 1b). To be fully comparable the selectivity to ethylene has been taken at $10 \%$ conversion and at a fixed reaction temperature of $300{ }^{\circ} \mathrm{C}$. As the catalysts present different reactivity $10 \%$ conversion at $300{ }^{\circ} \mathrm{C}$ has been obtained using different contact times for all catalysts.

As observed by Lemonidou there is a clear relationship between the incorporation of dopants with high valence $(+4$ or +5$)$ and the highest ethylene selectivity observed. In contrast if doped with potassium the selectivity is even lower than that of bare neat $\mathrm{NiO}$ (Fig. 1a).

One way to estimate the acidity/basicity of a metal oxide is through the concept of isoelectric point (IEP). IEP is the $\mathrm{pH}$ at which the surface does not possesses a net surface charge. Thus high IEP involves basicity of the metal oxide and low IEP acidity. Figure 1b shows the relationship between the selectivity to ethylene with the isoelectric point of the metal oxide promoter. As can be seen, the selectivity to ethylene is highest for those with the highest acidity (lowest IEP). This suggests that the acid/basic characteristics of the promoters likely modify the characteristics of nickel species. Moreover, if considered the valence of the dopant it can be seen that for a given oxidation state the higher selectivity is attained by those with the higher acidity.

On the other hand, one could expect a correlation between particle size and selectivity to ethylene. Figure 2 shows the XRD patterns of the different $\mathrm{NiO}$ based catalysts. As can be seen the main crystalline phases is $\mathrm{NiO}$ for all catalysts and in most cases the unique phase detected. It can be seen, according to the width of the peaks, that the crystallite size is highest for $\mathrm{NiO}$ whereas for all promoted $\mathrm{NiO}$ is remarkable lower. For pure NiO the mean crystallite size estimated by the Scherrer equation is of ca. $35 \mathrm{~nm}$ whereas for promoted $\mathrm{NiO}$ catalysts is in all cases lower than $20 \mathrm{~nm}$ and mostly in the 8 to $15 \mathrm{~nm}$ range. Only in the case of $\mathrm{NiAl}\left(\gamma-\mathrm{Al}_{2} \mathrm{O}_{3}\right)$, in which a salt of aluminium was not 
used in the preparation method but only diluted with $\gamma-\mathrm{Al}_{2} \mathrm{O}_{3}$, the crystallite size is only slightly smaller than that of pure NiO.

Figure 3 plots the selectivity to ethylene vs. the particle size of NiO. The relationship between these parameters is not so clear. However it seems that to attain a high ethylene production the crystallites of $\mathrm{NiO}$ does not have to be large.

Another aspect worthwhile to study is how the addition of promoters influence the total activity of the $\mathrm{NiO}$ catalysts. In this sense, the plots $\mathrm{T} 10$ (an inverse estimation of how active a catalyst is and in this case means the reaction temperature for a $10 \%$ conversion fixing the contact time in $80 \mathrm{gcat}_{\mathrm{cat}} \mathrm{h} / \mathrm{molC}_{2}$ ) has been correlated with the valence of the promoter (supplementary information, S1), the isoelectric point of the oxide of the promoter and the particle size. In general, clear trends have not been observed with any of the characteristics plotted.

In order to understand the effect of promoters on the catalytic behaviour of $\mathrm{NiO}$ particles, surface sensitive spectroscopic tools have been used. XPS spectroscopy, while is not a real surface sensitive characterisation method, gives average information of the first surface layers. In this sense the presence of different Ni sites, characterised by BE of 854.3 and $856.4 \mathrm{eV}$, can be evidenced depending on the promoter. Previous studies [18] have shown a clear correlation between the satellite1/main peak ratio and the ethylene selectivity, suggesting that non stoichiometric $\mathrm{Ni}^{2+}$ sites are involved in non selective process, i.e $\mathrm{CO}_{\mathrm{X}}$ formation. In this sense, the Ni2p3/2 XPS spectra of $\mathrm{NiO}$ promoted by several elements have been analysed and shown in Figure 4. The satellite main peak ratio is given in table 1 . While no clear correlation between selectivity and the satellite1/main peak ratio can be seen, some trend can be observed in the sense that the highest selectivity to ethylene is observed in the samples with the lowest satellite1/main peak ratio. This agrees with our previous results obtained on Sn promoted samples [18]. 
As indicated previously XPS gives average information of the $\mathrm{NiO}$ particle and no clear correlation with ethylene selectivity is obtained. However analysis of the uppermost surface is strongly required since catalytic processes takes place on the catalysts surface. Thus the nature of surface sites (i.e. coordination degree which lead to a specific Lewis acidity) play an important role in the activation of reactants and in the desorption of intermediate and reaction products, influencing in this way the activity and selectivity of the ODHE process.

It has been widely reported in the literature that $\mathrm{CO}$ is a valuable probe molecule for the identification of surface sites of different Lewis acidity, i.e., coordination state [18]. In this sense, FTIR of $\mathrm{CO}$ adsorption has been done on the $\mathrm{NiO}$ promoted samples (see supplementary information for IR spectra of adsorbed CO). At the same CO coverage, figure 5 shows comparatively the IR spectra in the $\mathrm{C} \equiv \mathrm{O}$ stretching vibration region of the different samples. IR bands at higher frequencies are normally related to a stronger metal surface acidity, while IR bands at lower frequencies are associated to less acidic Lewis sites. In this sense, the acidity of Lewis surface sites decrease in the order $\mathrm{Ni}-\mathrm{Nb}>\mathrm{Ni}-\mathrm{Sn}>\mathrm{Ni}-\mathrm{Zr}>\mathrm{Ni}-\mathrm{Al}>\mathrm{Ni}-\mathrm{ZrCe}>\mathrm{Ni}-\mathrm{Ce}-\mathrm{Zr}>\mathrm{Ni}-\mathrm{La}>\mathrm{NiO}>>\mathrm{Ni}-\mathrm{K}$. The trend in surface acid sites seems to correlate with the selectivity to ethylene except for the most acidic sample $\mathrm{N}$-iNb which shows similar selectivity that the immediately less acidic Ni-Sn promoted sample. This may suggest that relatively high surface acidity is required to obtain high selectivity to ethylene although also strong acid sites could difficult desorption of the reaction product leading to secondary non selective processes.

The role of the acid-base characteristics of the catalysts in the oxidative dehydrogenation of ethane has been reported to be very important $[6,29]$. Thus in vanadium oxide based catalysts, relatively acid supports have demonstrated to be highly selective to ethylene, whereas basic supports show low selectivity [6,30]. For example, in K-doped and K-free 
vanadium supported catalysts in spite of the fact that the nature of VOx active sites is substantially the same the selectivity to ethylene was very different, being higher for the K-free catalysts. This contrasts with the catalytic results in the ODH of longer chain alkanes as propane and especially butane with the K-containing catalysts being more selective to olefins than the K-free catalysts [31]. Therefore the number of acid sites of the catalysts must influence the adsorption/desorption properties of the catalysts thus affecting the catalytic performance. Thus acid supports can desorb more easily ethylene than other olefins such as propylene and butanes, likely due to the higher acid character of the $\mathrm{C}_{2}$ olefin. However, if the support is excessively acidic, such as in the case of $\mathrm{TiO}_{2}$, the formation of ethylene decreases [32].

Similarly, in the present paper we have observed that for promoted nickel catalysts those with high acidic character are the most selective to ethylene. In this case the nature of the nickel species is modified depending on the promoter, so at least two factors should be taking into account to explain the catalytic performance: i) the nature of the Ni-species and ii) the acidity/basicity of the catalyst. The valence of the promoter has been described to influence the nature of the $\mathrm{Ni}$ species, those with high valence decreasing the concentration of the unselective non-stoichiometric oxygen in $\mathrm{NiO}\left(\mathrm{Ni}^{3+}\right.$ species $)$ and obtaining higher selectivity to ethylene [15]. This trend has been corroborated in the present paper using other promoters. In fact less selective catalysts show a higher ratio of non-stoichiometric Ni sites as revealed by the XPS data. According to previous studies $(14,18)$ non-stoichiometric Ni sites favor the presence of electrophilic oxygen species, these being involved in non-selective processes. Additionally we have observed that for a given oxidation state the more acidic promoters exhibit higher selectivities to ethylene, highlighting the beneficial role of acid surface sites. 


\section{Conclusions}

In conclusion, The catalytic performance in the oxidative dehydrogenation and the physico-chemical characteristics of $\mathrm{NiO}$ can be modified by the incorporation of a second metal oxide as promoter. In this way manner, catalysts with a $\mathrm{Ni} /(\mathrm{Me}+\mathrm{Ni})$ atomic ratio of $0.92(\mathrm{Ni}=\mathrm{Nb}, \mathrm{Sn}, \mathrm{Ce}, \mathrm{Ce} / \mathrm{Zr}, \mathrm{Al}, \mathrm{La}, \mathrm{K})$ have been prepared, characterized and tested. Both the valence and the acid/base characteristics of the metal oxide promoter have a strong influence on the selectivity to ethylene. An analysis of the nature of nickel surface sites on the promoted $\mathrm{NiO}$ catalysts have shown show that non-stoichiometric nickel sites are involved in non selective catalytic processes, due to the stabilization of electrophilic oxygen species. On the other hand Additionally it is shown that there is exists a parallelism between the formation of ethylene and the concentration and strength of surface acidity. In this way Therefore, $\mathrm{Nb}$ - and Sn- seem to be are the more most selective ones dopants whereas while La- and K-doped catalysts are the less least selective ones; the rest of the catalysts presenting an exhibit intermediate selectivity to ethylene, depending on their respective acid characteristics.

\section{Acknowledgements}

The Spanish authors would like to thank the DGICYT in Spain (Project CTQ201237925-C03-1 and CTQ2012-37925-C03-3) for financial support.

\section{References}

[1] Lippe D (2013) Oil \& Gas J 111: 3.

[2] True WR (2010) Oil \& Gas J. 0, 108: 34.

[3] Ren T, Patel MK, Blok K (2008) Energy 33: 817.

[4] Cavani F, Ballarini N, Cericola A (2007) Catal. Today 127: 113. 
[5] a) Bhasin MM (2003) Top. Catal. 23: 145; b) Bhasin MM, McCain JH, Vora BV, Imai T, Pujadó PR (2001) Appl. Catal. A: Gen 221: 397.

[6] Blasco T, López Nieto JM (1997) Appl. Catal. A: Gen 157: 117.

[7] Bañares MA (1999) Catal Today 51:319

[8] Grzybowska-Świerkosz B (2000) Top Catal 11-12: 23

[9] Davies TE, García T, Solsona B, Taylor SH (2006) Chem. Commun. 32: 3417.

[10] Sri Hari Kumar A, Upendar K, Qiao A, Rao PSN, Lingaiah N, Kalevaru VN, Martin A, Sailu Ch, Sai Prasad PS (2013) Catal. Commun. 3376-79.

[11] Frank B, Morassutto M, Schomacker R, Schlogl R, Sheng Su D (2010) ChemCatChem 2: 644.

[12] Skoufa Z, Heracleous E, Lemonidou AA (2012) Catal. Today 192: 169.

[13] Heracleous E, Lee AF, Wilson K, Lemonidou AA (2005) J. Catal. 231: 159.

[14] Heracleous E, Lemonidou AA (2006) J. Catal. 237: 162.

[15] Heracleous E, Lemonidou AA (2010) J. Catal. 270: 67.

[16] Zhu H, Ould-Chikh S, Anjum DH, Sun M, Biausque G, Basset JM, Caps V (2012) J. Catal. 285: 292.

[17] Savova B, Loridant S, Filkova D, Millet JMM (2010) Appl. Catal. A: Gen 390: 148.

[18] Solsona B, Concepción P, Demicol B, Hernández S, Delgado JJ, Calvino JJ, López Nieto JM (2012) J Catal 295: 104.

[19] Solsona B, Dejoz AM, Vázquez MI, Ivars F, López Nieto JM (2009) Top Catal 52: 751.

[20] Solsona B, López Nieto JM, Concepción P, Dejoz A, Ivars F, Vázquez MI (2011) J. Catal 280: 28.

[21] Skoufa Z, Heracleous E, Lemonidou AA, (2012) Chem Eng Sci 84: 48.

[22] Lin X, Xi Y, Sun J (2012) J. Phys Chem C 116: 3503. 
[23] López Nieto JM, Botella P, Vázquez MI, Dejoz A (2002) Chem. Commun.17: 1906.

[24] Solsona B, Vázquez MI, Ivars F, Dejoz A, Concepción P, López Nieto JM (2004) J. Catal 252: 271.

[25] Nguyen TT, Aouine M, Millet JMM (2012) Catal Commun 21 :22.

[26] Ischenko EV, Andrushkevich TV, Popova GYa, Bondareva VM, Chesalov YA, Kardash TYu, Plyasova LM, Dovlitova LS, Ischenko AV (2010) Stud Surf Sci Catal 175: 479.

[27] Choudhary TV, Banerjee S, Choudhary VR (2002) Appl Catal A: Gen 234:1.

[28] Bortolozzi JP, Gutierrez LB, Ulla MA (2013) Appl Catal A: Gen 452:179.

[29] Concepción P, López Nieto J.M, Pérez-Pariente J, (1994) Catal. Lett., 28:9.

[30] Kao CY, Huang KT, Wan BZ, (1994) Ind. Eng. Chem. Res., 33:2066.

[31] Galli A, López Nieto JM, Dejoz A, Vázquez MI, (1995) Catal. Lett., 34:51.

[32] Heracleous E, Machli M, Lemonidou AA, Vasalos IA, (2005) J. Mol. Catal. A: Chem. 232: 29. 


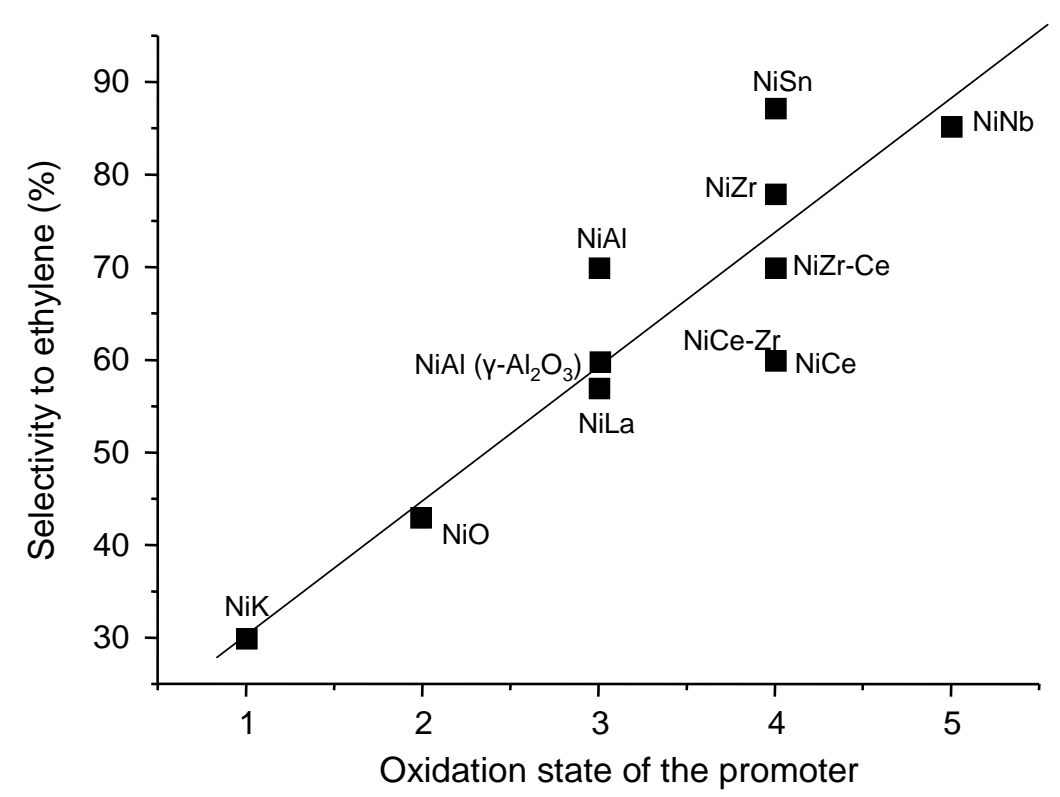

Figure 1a

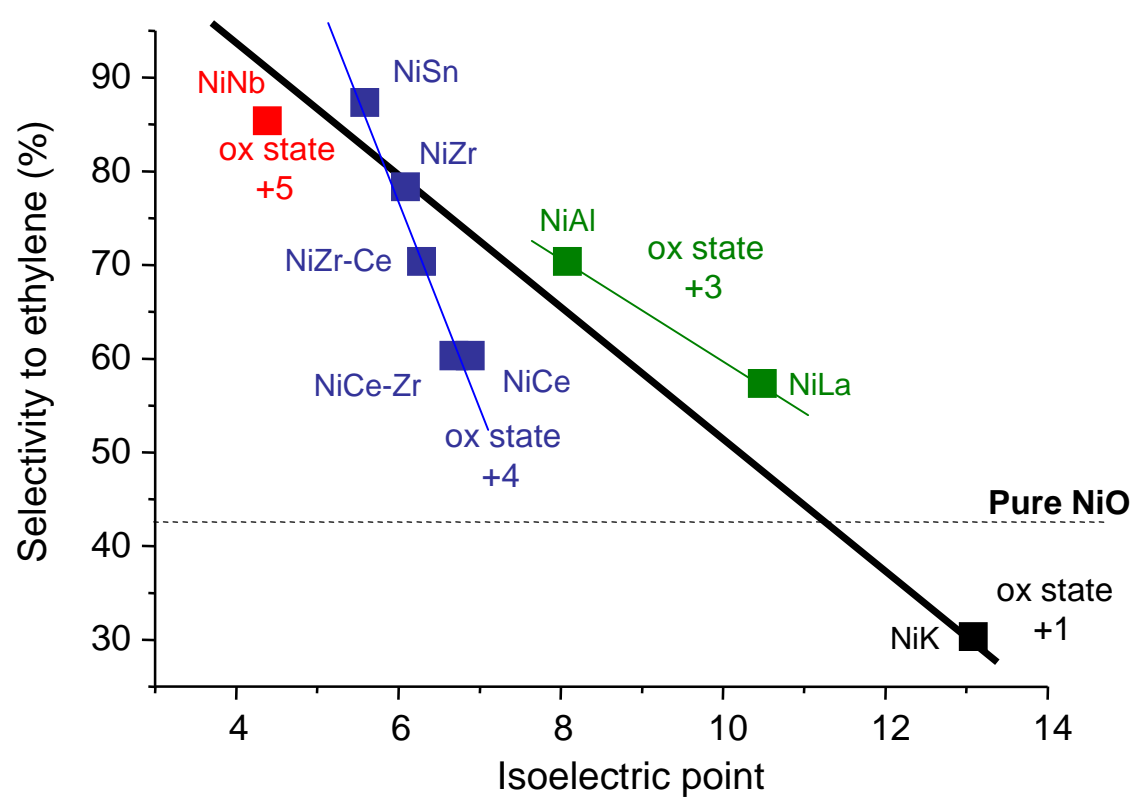

Figure1b

Fig.1. Variation of the selectivity to ethylene with the oxidation state (a) and the isoelectric point of the metal oxide promoter (b). 


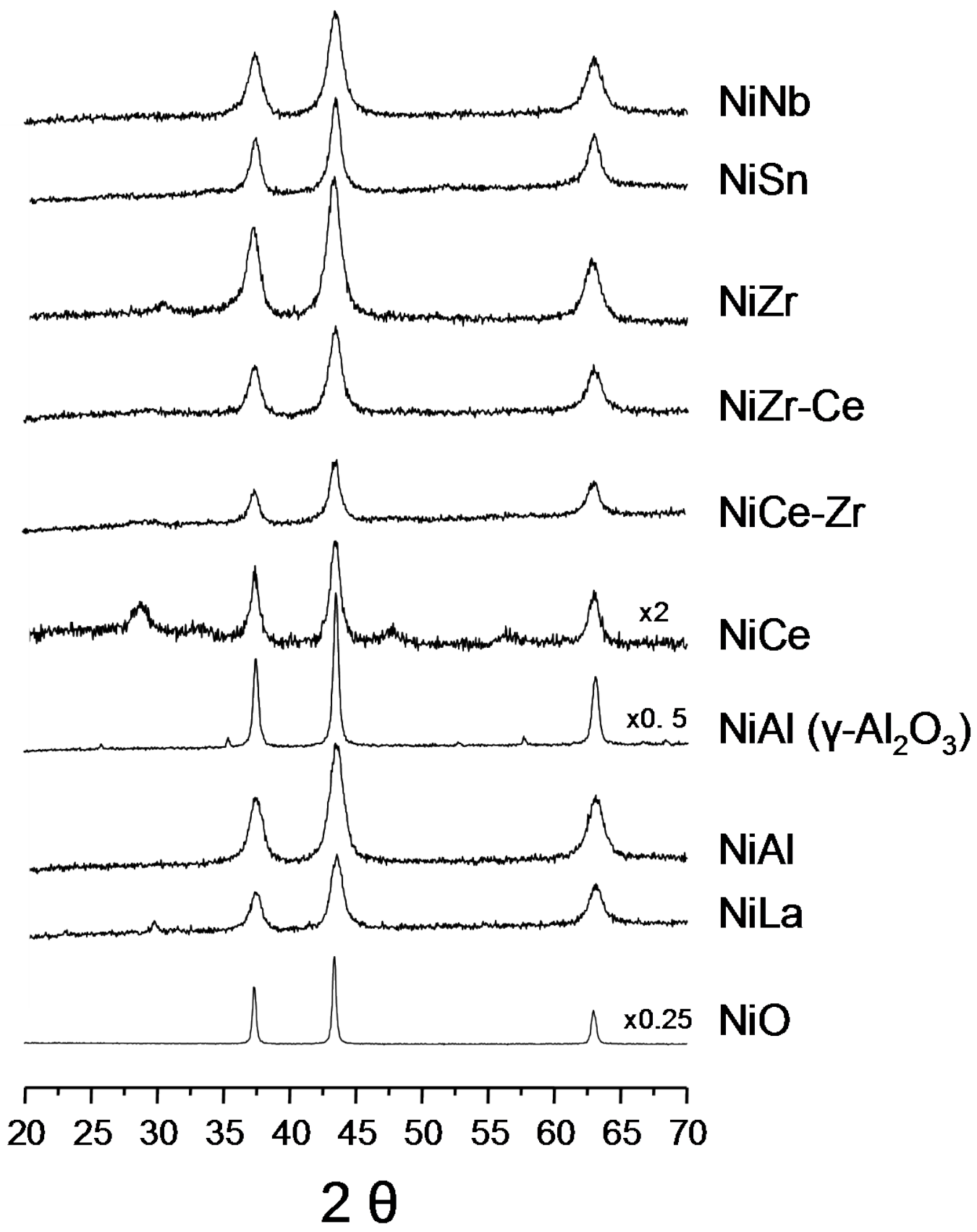

Fig.2. XRD patterns of catalysts. 


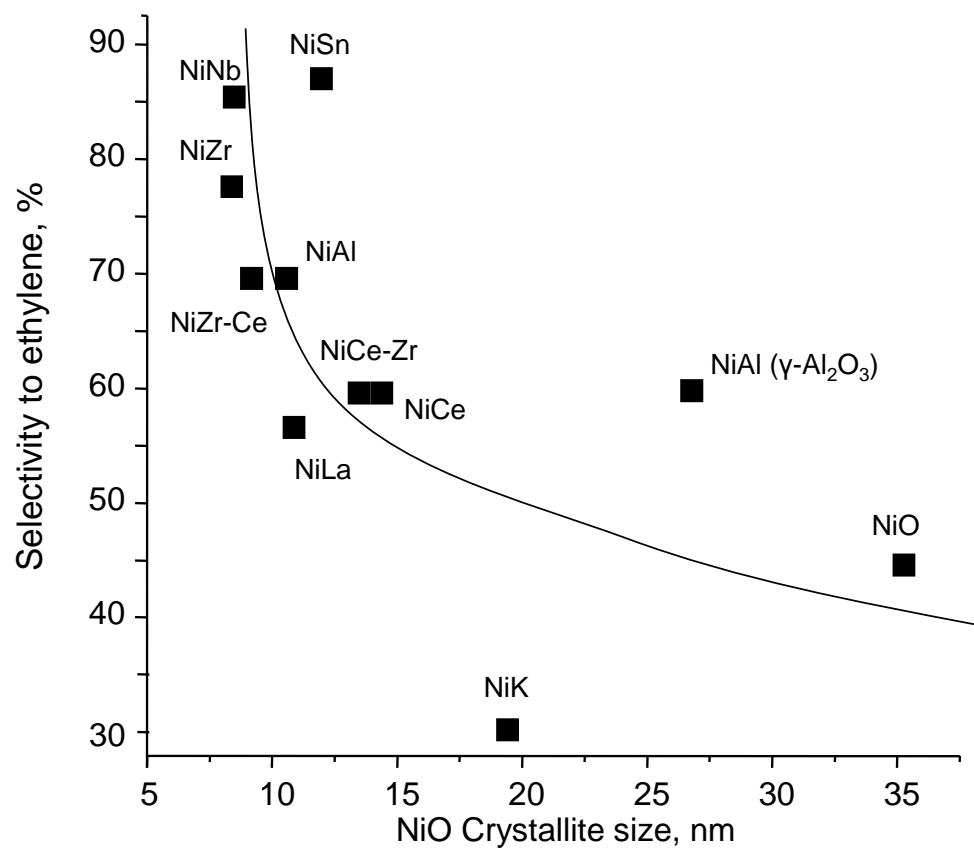

Fig.3. Variation of the selectivity to ethylene with the crystal size of $\mathrm{NiO}$ 


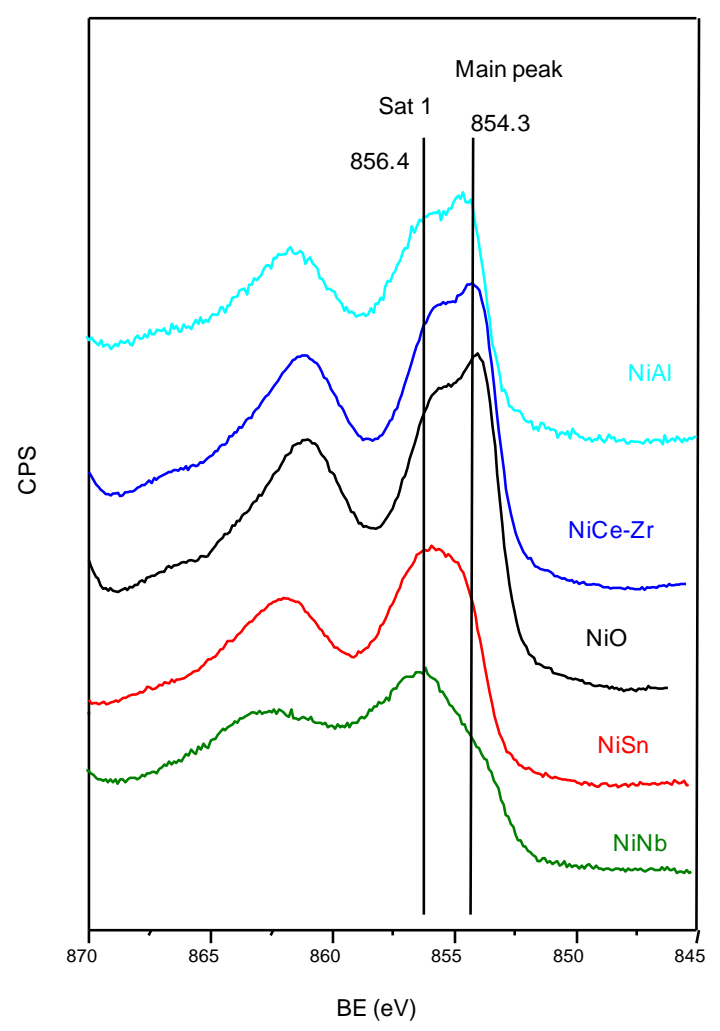

Fig.4. X-ray photoelectron spectra of Ni2p3/2 of promoted catalysts 

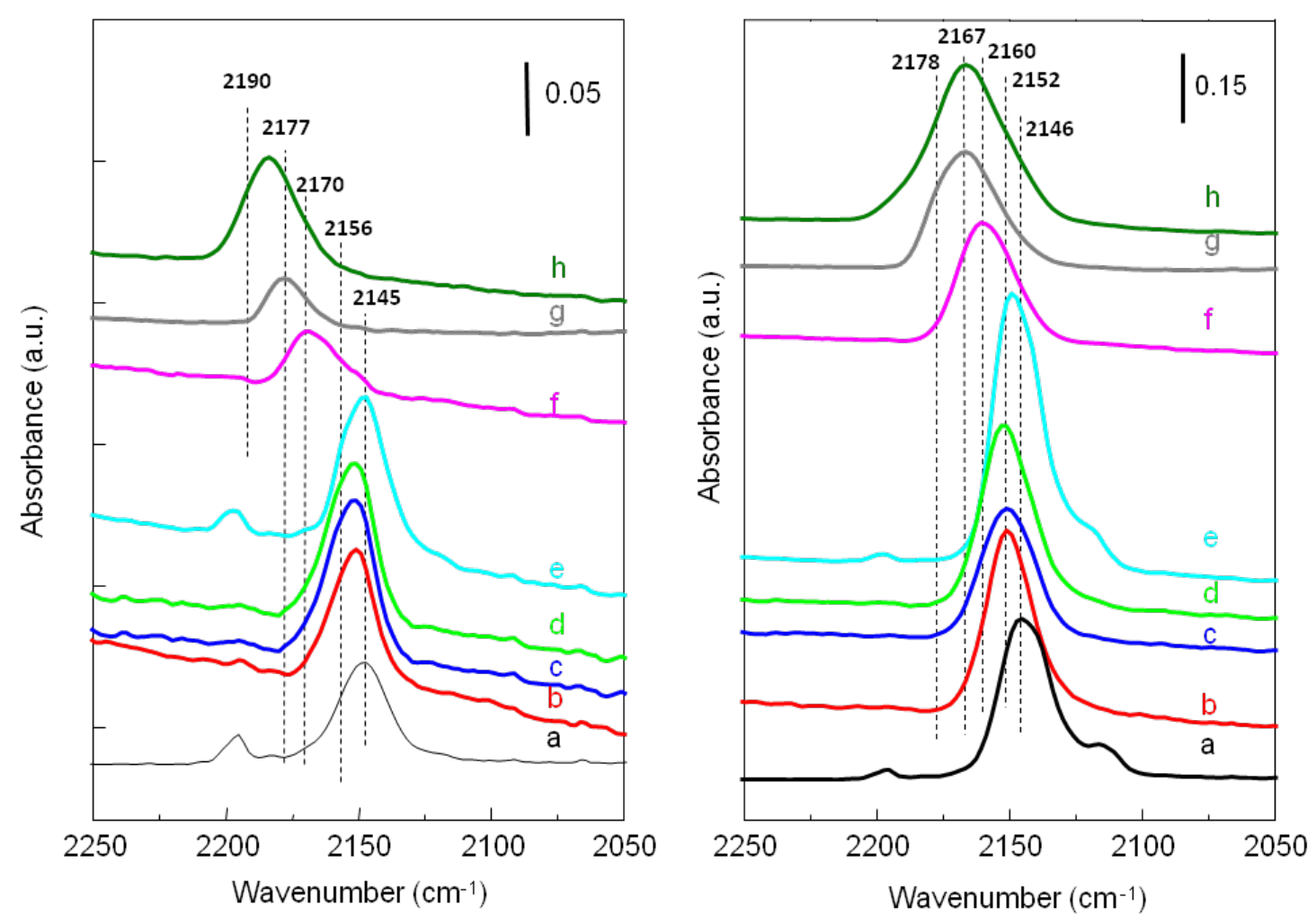

Fig.5. FTIR spectra in the CO stretching vibration of NiO promoted samples at 0.2 mbar (left) and 1 mbar (right): a) NiO; b) Ni-La; c) Ni-CeZr; d) Ni-ZrCe; e) Ni-Al; f) Ni-Zr; g) Ni-Sn; h) Ni-Nb. 
Table 1. Physico-Chemical Characteristics of Ni-based catalysts.

\begin{tabular}{|c|c|c|c|c|}
\hline Catalyst & $\begin{array}{l}\text { NiO Crystal size } \\
(\mathrm{nm})^{3}\end{array}$ & $\begin{array}{l}\text { Selectivity to } \\
\text { Ethylene (\%) }\end{array}$ & $\begin{array}{l}\text { XPS, Ni2p3/2 } \\
\text { sat1/main peak }{ }^{4}\end{array}$ & $\begin{array}{l}\text { CO adsorption } \\
\text { (CO-ad) }^{5}\end{array}$ \\
\hline $\mathrm{NiO}$ & 35 & 43 & 1.5 & 0.1 \\
\hline Ni-Nb & 9 & 86 & 0.9 & 14.9 \\
\hline Ni-Sn & 12 & 87 & 1.22 & 14.1 \\
\hline $\mathrm{Ni}-\mathrm{Zr}$ & 9 & 78 & nd & nd \\
\hline Ni-Al & 11 & 70 & 1.57 & 2.4 \\
\hline $\mathrm{Ni}-\mathrm{Ce}$ & 15 & 59 & 1.52 & n.d \\
\hline $\mathrm{Ni}-\mathrm{ZrCe}{ }^{1}$ & 10 & 70 & 1.51 & 7.3 \\
\hline $\mathrm{Ni}-\mathrm{CeZ} \mathbf{r}^{2}$ & 12 & 59 & 1.4 & 6.6 \\
\hline Ni-La & 11 & 56 & n.d & 5.1 \\
\hline Ni-K & 20 & 29 & n.d & 0 \\
\hline
\end{tabular}

1) NiZrCe ; 2) NiCeZr; 3) Determined from XRD; 4) determined from XPS; 5) determined from FTIR of adsorbed CO on surface sites with acidity higher than that observed on $\mathrm{NiO}$ (IR bands at frequency higher than $2145 \mathrm{~cm}^{-1}$ ). 
Supplementary information (S-1)
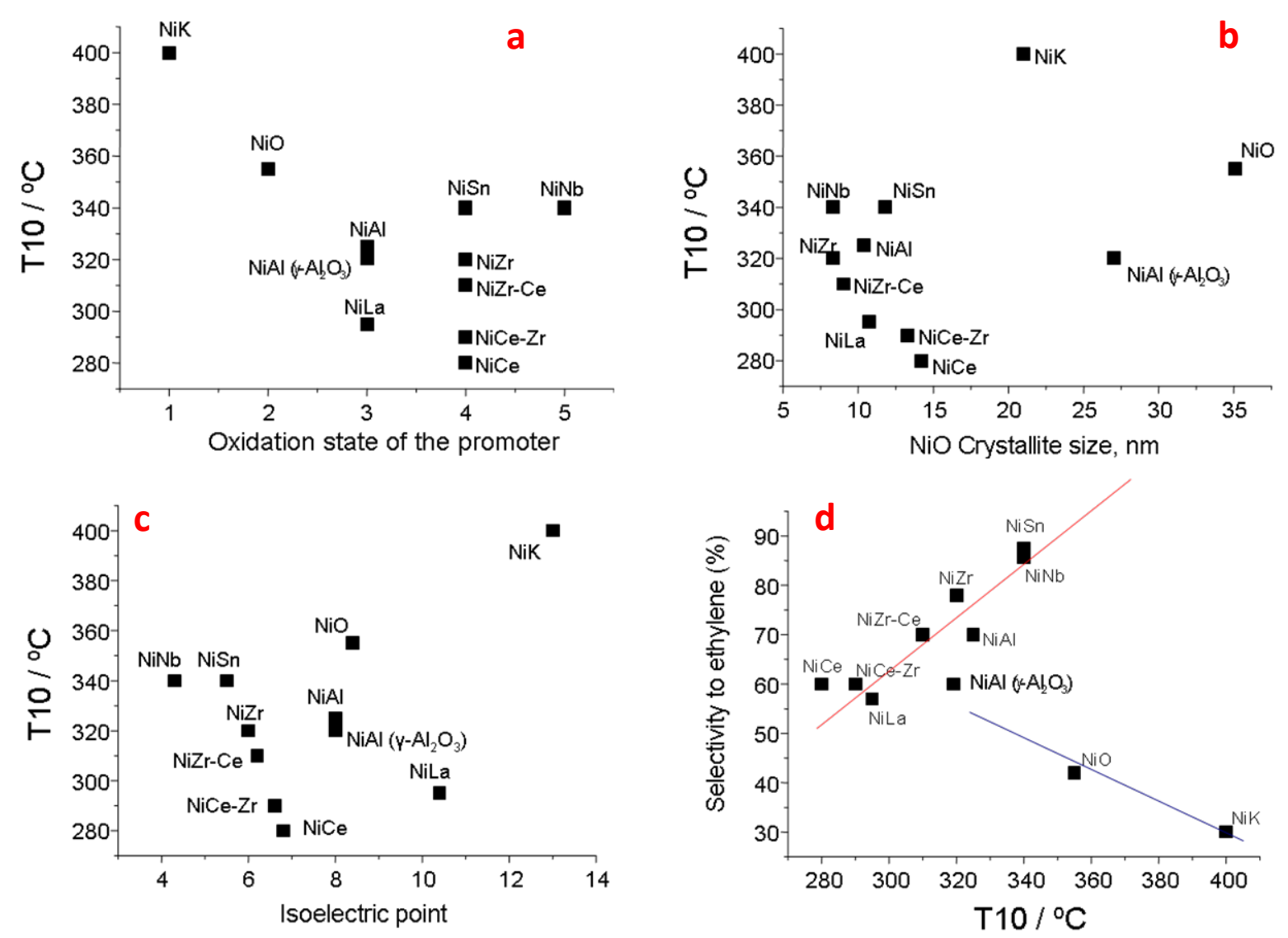


\section{Supplementary information (S-2)}
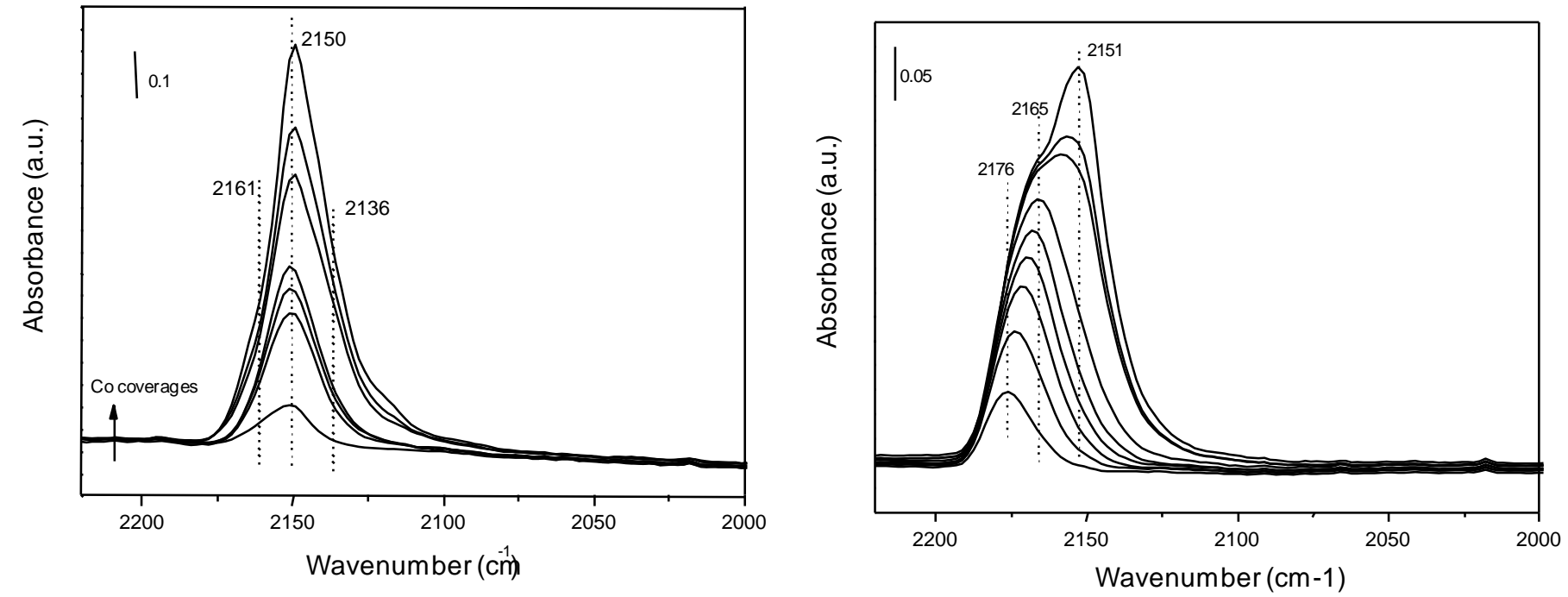

Suplementary information S-2: FTIR spectra of CO adsorption at increasing CO coverages (from 0.2 mbar to 2 mbar): a) Ni-La; b) Ni-Sn. 